\title{
Solar Energy Induced Woody Biomass Conversion with a Semiconductor Photoelectrode
}

\author{
Claire Y. Lee, Alicia Y. Leem, Hannah Park \\ Fayetteville-Manlius High School, 8201 E Seneca Turnpike, Manlius, New York 13104, USA; clairelee5g@gmail.com, \\ yuminleem@gmail.com
}

ABSTRACT: An abundance in lignocellulosic biomass can be an effective solution for increasing fuel and chemical demands. Lignocellulosic biomass is composed of cellulose, hemicellulose, and lignin - all components that are vital to its ability to be converted into various value-added chemicals. Despite its abundance and subsequent potential, the depolymerization of lignin remains a big technical challenge. This experiment entailed the oxidation of corn stover with the dye sensitized solar cell (DSSC) as a pretreatment process for easy depolymerization. In the photoelectrochemical reaction, raspberry extract coated titanium dioxide $\left(\mathrm{TiO}_{2}\right)$ electrode and a visible LED light source were used to see if solar energy could be used. It was observed that the absorption spectra changes, which infers structural changes in corn stover through UV-vis spectroscopy, finding the possibility of depolymerization of lignin in mild conditions at a low cost.

KEYWORDS: Energy; Chemical; Solar Materials; Woody biomass; Photoelectrochemical Cell; Sustainable Energy. Manhattan had a more pronounced upward when compared to the data gathered from the stations in relatively less populated areas.

\section{Introduction}

Wood is composed of three components: microfibrils of cellulose (35-50\%), hemicellulose (20-35\%), and lignin (15-20\%) - all shown in Figure 1. Lignin is the largest non-carbohydrate component in the lignocellulosic biomass (LCB) and the most abundant aromatic polymer (LCB contains up to $20 \%$ lignin) but is currently underutilized. Most of the lignin is used for producing heat energy but instead, it can be converted to valuable chemicals (i.e. ethanol, phenol). ${ }^{1}$ Previous studies show that lignin can be decomposed at high temperatures and pressure, resulting in the production of value-added chemicals. ${ }^{2}$ Recently, several research groups developed effective methods to break down lignin into small molecules by utilizing visible or solar light, a naturally abundant, safe, and cost efficient source. ${ }^{3}$ More importantly, these solar-powered reactions allow for improvement in selectivity and the yield of lignin decomposed, especially under mild conditions such as room temperature air. Inspired by the recent studies about visible light induced lignin depolymerization, a unique method was reported to modify lignin into decomposed lignin with a dye-sensitized solar cell under the illumination of visible light. Composed of light absorbing molecules, fruit dyes extracted from raspberries, blueberries, and blackberries were utilized as a component of the dye sensitized solar cell, because it can absorb photons which make up light.

Solar energy is considered an alternative renewable and sustainable energy source. As a result of using fossil fuels, global warming and air pollution are problems that substantially degrade the environment today. In 2017, 81\% of the world's consumed energy was oil, coal, and natural gas and nearly fifteen billion metric tons of fossil fuels are consumed every year. ${ }^{4}$ At this rate, it's predicted that the world will run out of fossil fuels in seventy years' time. ${ }^{5}$ Not only is this a strain on our available energy sources, but it presents a health crisis as well.
The resulting air pollution alone, which has been on the rise since 2016 , contributes to $9 \%$ of global deaths. ${ }^{6}$

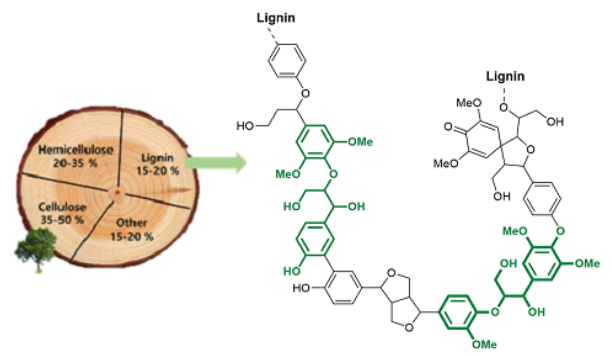

Figure 1: · Wood components and the structure of lignin (The green lined structures represent the major molecular structure in lignin).

To find a solution to this global issue, researchers are creating modernized ways to acquire energy by using natural resources such as solar radiation. Among these modernized alternatives is the dye sensitized solar cell. These cells produce electric energy by absorbing the rich visible light radiated from the sun and applying the principles of plant photosynthesis (Figure 2). The process of chlorophyll utilizing solar energy is mimicked by the dye in these cells. Similar to how plants absorb solar energy to turn it into chemical energy, these cells are able to absorb solar energy and process it into usable electric energy as shown in Figure 3. Like the process of photosynthesis where chloroplasts capture light energy to convert into chemical energy (ATP, NADPH in chloroplast), the fruit dye in the dye sensitized solar cell attaches to the $\mathrm{TiO}_{2}$ particles to absorb light. The dye then gives its electrons to allow the flow of energy throughout the cell, which is kept in a cycle by the iodine mediator that is added.

\section{Goal of the project:}

In the following project, the isolated lignin gained from a range of pretreatments will be used as feedstock to produce mono-aromatic compounds and/or dicarboxylic acids. A 
range of aromatic compounds, often used as another renewable source for petroleum-based chemical building blocks, will be produced from lignin through depolymerization with a final goal of improving the economics of LCB- based biorefineries.

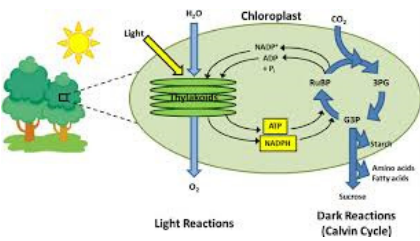

Figure 2: Process of photosynthesis.?

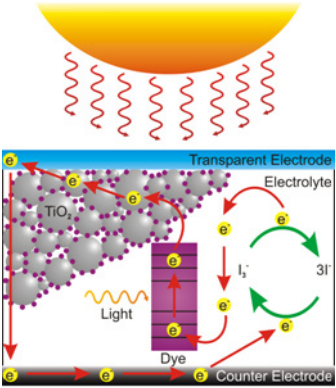

Figure 3: Process of dye sensitized solar cell. ${ }^{8}$
As a pretreatment process, the dye sensitized solar cell was fabricated and checked for the possibility of lignin depolymerization in corn stover through photo-oxidation using solar energy. Corn stover is the non-grain portion of corn crop and considered to be a substantial potential biorefining resource and often used for lignin decomposition research. Untreated corn stover has $20 \%$ lignin.

\section{- Methods \\ Chemicals:}

Sunscreen (Bare republic, Titanium Dioxide 6.4\%), raspberries, blueberries, and blackberries were purchased from Wegmans, NY. Isopropyl alcohol ( 99\%) was purchased from Amazon. Hydrogen peroxide (3\%) and acetone ( 99\%) were purchased from CVS without the purification. The Leem and Yoo research groups at SUNY ESF provided $\mathrm{TiO}_{2}$ paste, corn stover, FTO glass, and electrolyte solution.

\section{General fabrication of Dye Sensitized Solar Cells:}

The three dyes were extracted from blueberries, raspberries, and blackberries by crushing the fruit and filtering out the dye using vacuum filtration. The dyes were then diluted with water and each was used to measure the UV-visible absorbance spectrum to understand the absorption of the dyes. The next step was to fabricate the dye sensitized solar cell using sunscreen containing $\mathrm{TiO}_{2}$ and other ingredients. Before applying anything to the fluorine doped tin oxide (FTO) glass, it was placed in isopropyl alcohol for ten minutes in the sonicator to cleanse the glass surface of any small particles. After the glass was cleansed, the sunscreen was evenly coated on the FTO glass by using different layers of tape on the perimeter to create various thicknesses and placed in the oven at $120{ }^{\circ} \mathrm{C}$ for one hour. After depositing the sunscreen on FTO glass at high temperature, the concentrated dye solution from fruit juice was dropped on top of the dry sunscreen coated FTO glass. After twenty minutes, any excess dye on the glass was gently rinsed off with solvents. The counter electrode was then prepared, which was a carbon coated FTO glass made by using graphite pencil. The two glass pieces, one with the fruit dye coated $\mathrm{TiO}_{2}$ containing sunscreen and the other electrode with the carbon coating, were sandwiched together and held together with two binder clips. Drops of redox elec- trolyte solution ( $0.5 \mathrm{M}$ iodide electrolyte solution) were then placed between the two glass samples and spread throughout its inner surface by clipping and unclipping the binder clips. ${ }^{9}$ The cell was assembled with an electric wire connected to a multimeter, which was used to find the maximum current of the cell when placed in front of different LED light sources, Red, Green, and Blue.

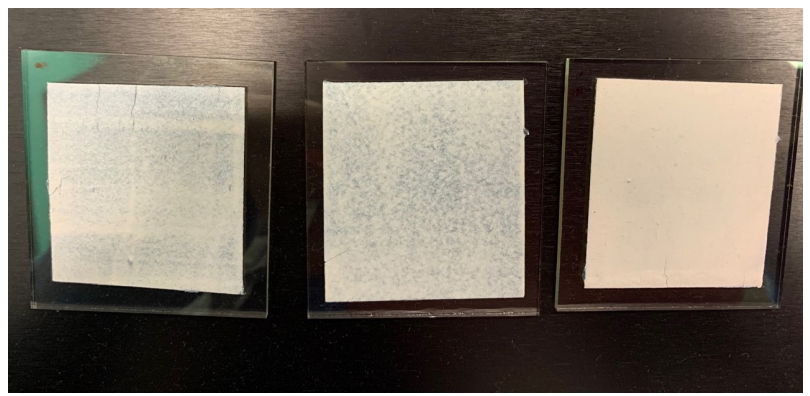

Figure 4: FTO glass substrate coated with sunscreen containing $\mathrm{TiO}_{2}$ with various thickness. (from left 1 layer, 2 layers and 3 layers of tape)

Instead of a small component of $\mathrm{TiO}_{2}$ in sunscreen, another dye-sensitized solar cell was prepared by using pure $\mathrm{TiO}_{2}$ paste and graphite carbon. Various samples of glass were evenly coated with $\mathrm{TiO}_{2}$ (Figure 4). The active area was controlled by adjusting the number of layers of scotch tape placed around the edges. When all the glass samples were coated with $\mathrm{TiO}_{2}$ paste, they were then placed on a hot plate at $80^{\circ} \mathrm{C}$ for twenty minutes. After drying, the concentrated raspberry dye solution was dropped on the preheated $\mathrm{TiO}_{2}$ electrode (Figure 5). The counter electrode, carbon coated FTO glass, was fabricated by coating the conductive side of the glass with graphite pencil. Then, the two electrodes, the dye attached $\mathrm{TiO}_{2}$ electrode, and the carbon coated FTO electrode, were sandwiched and held together with two binder clips. Iodide electrolyte solution was dropped between the two glass samples and spread throughout the inner surface by clipping and unclipping the binder clips. The electrodes, with an electric wire, were connected to a multimeter which was used to find the maximum current of the cell in Figure 6 and $7 .^{10}$ The photocurrent density data was obtained with different distances between the electrodes and the different LED light sources: Red, Green, and Blue.

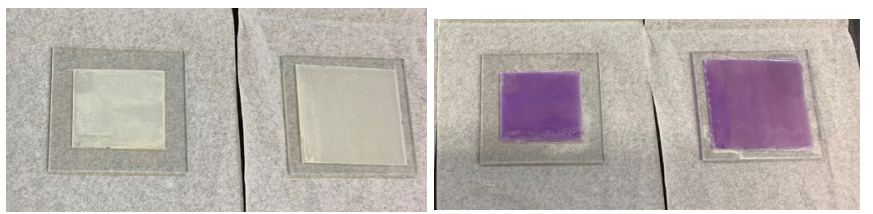

Figure 5: FTO glass substrate coated with $\mathrm{TiO}_{2}$ paste and raspberry extract.
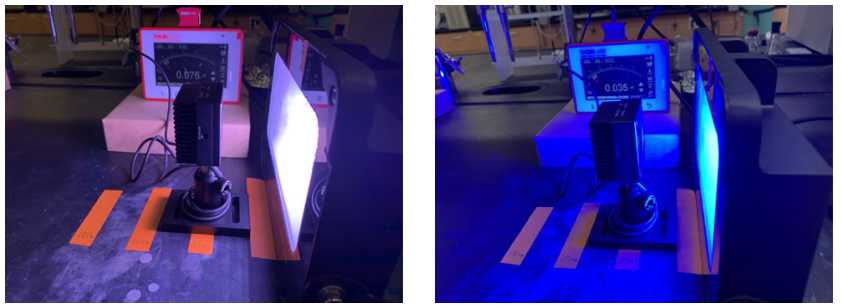

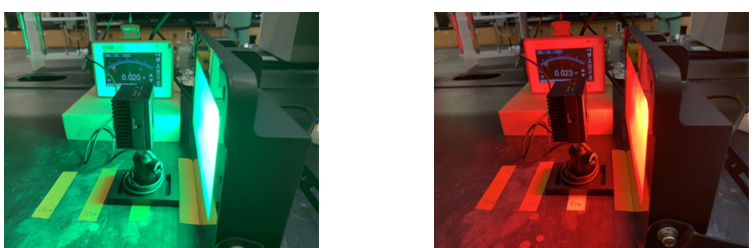

Figure 6: Measuring light intensity with optical power meter in various distance and various light colors.

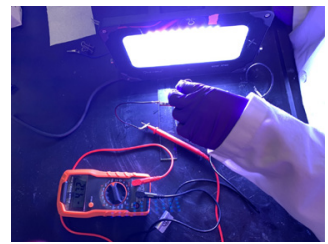

Figure 7: Measuring electrical current of DSSC with multimeter.

\section{Photoelectrochemical Oxidation of Lignin:}

In a $100 \mathrm{ml}$ beaker, $10 \mathrm{ml}$ of acetone and $20 \mathrm{ml}$ of 3\% hydrogen peroxide were put in water as an oxidizing agent. In addition, $1.0 \mathrm{~g}$ of corn stover was added. To set up the photoelectric oxidation experiment, the raspberry dye coated $\mathrm{TiO}_{2}$ electrode was used as a working electrode. Then, platinum wire was used as a counter electrode and an $\mathrm{Ag} / \mathrm{AgCl}$ electrode as a reference electrode. The solution was heated to $60^{\circ} \mathrm{C}$ for an hour shown in Figure 8. ${ }^{10,11}$ The photocurrent, approximately $10^{-6} \mathrm{~A} / \mathrm{cm}^{2}$, was monitored under visible light illumination.

In another $100 \mathrm{ml}$ beaker, the same procedures were followed as above except for the absence of electrodes as a control experiment in order to compare the effectiveness of the dye sensitized solar cell (Figure 8).
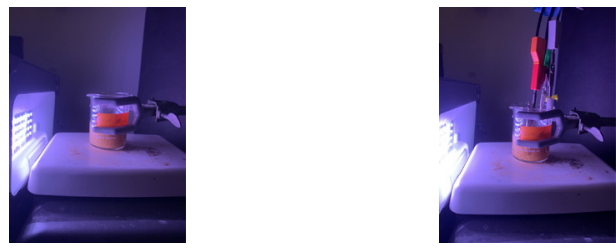

Figure 8: Photoelectrochemical oxidation experiment of corn stover.

\section{Results and Discussion}

\section{$U V$-visible absorbance spectra of various fruit dyes:}

In Figure 9, maximum absorbance in the visible light range was $494 \mathrm{~nm}$ for blackberries and $508 \mathrm{~nm}$ for raspberries, but the blueberry dye solution barely showed any peak in the visible range. Previous studies reported the broad absorption of light between 400 and $600 \mathrm{~nm}$ in blackberry. ${ }^{12}$ This UV-vis data is largely consistent with our observation based on the visible absorbance spectrum of the blackberry dye. According to the solar radiation spectrum, visible light is most abundant between $400 \mathrm{~nm}$ and $700 \mathrm{~nm}$ (Figure 10). To maximize the usage of solar energy, fruit dyes are appropriate due to their absorption in the visible region. Among the fruits, raspberry dye was chosen based on its efficient absorption in the visible range, showing it can absorb the most visible light for the use of dye sensitized solar cells.

\section{Dye Sensitized Solar Cell (DSSC) with Sunscreen:}

$\mathrm{TiO}_{2}$ is widely used as a semiconductor in DSSCs because it is easy to synthesize and has a low cost. Sunscreen, which contains $\mathrm{TiO}_{2}$, was used for the DSSC tests. Unfortunately, a photocurrent was not detected due to the small amount of
$\mathrm{TiO}_{2}(6.4 \%)$ and other organic ingredients in the sunscreen.

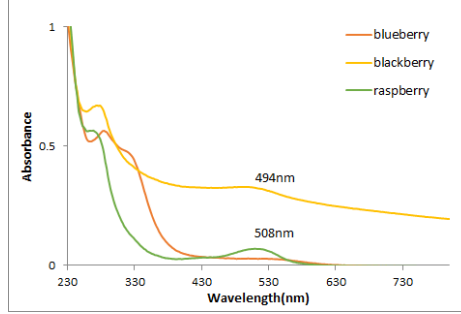

Figure 9: UV-vis absorption spectrum of various fruit extracts

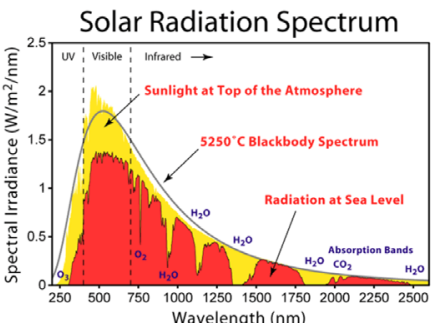

Figure 10: Solar radiation spectrum.

Dye Sensitized Solar Cell (DSSC) with $\mathrm{TiO}_{2}$ Paste:

Using an LED light source, the electrical currents were measured from (1) the different active areas and (2) the distance between the light source and the DSSC. Interestingly, it was observed that greater surface areas with closer distances to the light source produced higher electrical currents (Table 1). Essentially, the closer distance between the light source and the DSSC exhibited higher light intensity and the larger surface area allowed for more light absorption. In Figure 11, the electrical current was plotted per $\mathrm{cm}^{2}$ versus power density. Based on this graph, it was concluded that the two measurements were very similar at the same distance.

Table 1: Measurement of electrical current in various areas and distances.

\begin{tabular}{|c|c|c|c|}
\hline Distance & Light Intensity & $4.5 \mathrm{~cm}^{*} 5 \mathrm{~cm}$ & $3.5 \mathrm{~cm}^{*} 4 \mathrm{~cm}$ \\
\hline $5 \mathrm{~cm}$ & $76 \mathrm{~mW} / \mathrm{cm}^{2}$ & $53.7 \mu \mathrm{A}\left(2.39 \mu \mathrm{A} / \mathrm{cm}^{2}\right)$ & $37.2 \mu \mathrm{A}\left(2.66 \mu \mathrm{A} / \mathrm{cm}^{2}\right)$ \\
\hline $10 \mathrm{~cm}$ & $36 \mathrm{~mW} / \mathrm{cm}^{2}$ & $47.2 \mu \mathrm{A}\left(2.10 \mu \mathrm{A} / \mathrm{cm}^{2}\right)$ & $31.8 \mu \mathrm{A}\left(2.27 \mu \mathrm{A} / \mathrm{cm}^{2}\right)$ \\
\hline $15 \mathrm{~cm}$ & $19 \mathrm{~mW} / \mathrm{cm}^{2}$ & $39.6 \mu \mathrm{A}\left(1.76 \mu \mathrm{A} / \mathrm{cm}^{2}\right)$ & $27.3 \mu \mathrm{A}\left(1.95 \mu \mathrm{A} / \mathrm{cm}^{2}\right)$ \\
\hline
\end{tabular}

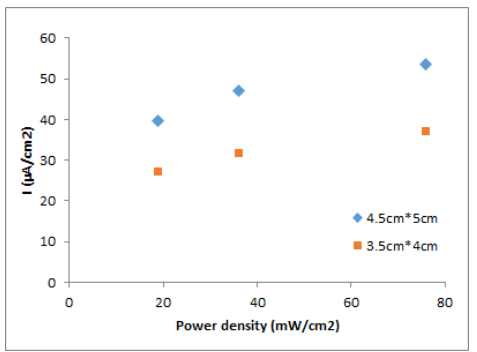

Figure 11: Graph of power density vs electrical current

Measurements of the Electrical Current by Colors of the Light
Source:
The wavelengths varied based on the colors of the light
source (Table 2). Out of the three colors that were experi-
mented (blue, green, red), the blue light produced the highest
electrical current. From the previous experiment above, it was
shown that the raspberry dye absorbs the most visible light in
the blue wavelength. This evidence explains how the blue light
produced the most electrical current.


Table 2: Measurement of electrical current with various light colors.

\begin{tabular}{|c|c|c|c|c|}
\hline light color & Distance & light intensity & $2 \mathrm{~cm}^{\star} 2 \mathrm{~cm}$ & $4 \mathrm{~cm}^{*} 4 \mathrm{~cm}$ \\
\hline \multirow{3}{*}{ white } & $5 \mathrm{~cm}$ & $76 \mathrm{~mW} / \mathrm{cm}^{2}$ & $9.8 \mu \mathrm{A}$ & $12.4 \mu \mathrm{A}$ \\
\cline { 2 - 5 } & $10 \mathrm{~cm}$ & $36 \mathrm{~mW} / \mathrm{cm}^{2}$ & $8.8 \mu \mathrm{A}$ & $10.2 \mu \mathrm{A}$ \\
\cline { 2 - 5 } & $15 \mathrm{~cm}$ & $19 \mathrm{~mW} / \mathrm{cm}^{2}$ & $8.2 \mu \mathrm{A}$ & $8.6 \mu \mathrm{A}$ \\
\hline \multirow{4}{*}{ blue } & $5 \mathrm{~cm}$ & $35 \mathrm{~mW} / \mathrm{cm}^{2}$ & $9.0 \mu \mathrm{A}$ & $10.8 \mu \mathrm{A}$ \\
\cline { 2 - 5 } & $10 \mathrm{~cm}$ & $16 \mathrm{~mW} / \mathrm{cm}^{2}$ & $8.6 \mu \mathrm{A}$ & $8.3 \mu \mathrm{A}$ \\
\cline { 2 - 5 } & $15 \mathrm{~cm}$ & $8 \mathrm{~mW} / \mathrm{cm}^{2}$ & $8.2 \mu \mathrm{A}$ & $6.5 \mu \mathrm{A}$ \\
\hline \multirow{4}{*}{ green } & $5 \mathrm{~cm}$ & $20 \mathrm{~mW} / \mathrm{cm}^{2}$ & $7.4 \mu \mathrm{A}$ & $7.9 \mu \mathrm{A}$ \\
\cline { 2 - 5 } & $10 \mathrm{~cm}$ & $9 \mathrm{~mW} / \mathrm{cm}^{2}$ & $6.3 \mu \mathrm{A}$ & $6.2 \mu \mathrm{A}$ \\
\cline { 2 - 5 } & $15 \mathrm{~cm}$ & $4 \mathrm{~mW} / \mathrm{cm}^{2}$ & $5.7 \mu \mathrm{A}$ & $5.9 \mu \mathrm{A}$ \\
\hline \multirow{3}{*}{ red } & $5 \mathrm{~cm}$ & $23 \mathrm{~mW} / \mathrm{cm}^{2}$ & $4.8 \mu \mathrm{A}$ & $7.7 \mu \mathrm{A}$ \\
\cline { 2 - 5 } & $10 \mathrm{~cm}$ & $10 \mathrm{~mW} / \mathrm{cm}^{2}$ & $4.6 \mu \mathrm{A}$ & $5.8 \mu \mathrm{A}$ \\
\cline { 2 - 5 } & $15 \mathrm{~cm}$ & $5 \mathrm{~mW} / \mathrm{cm}^{2}$ & $4.5 \mu \mathrm{A}$ & $4.7 \mu \mathrm{A}$ \\
\hline
\end{tabular}

Photoelectrochemical oxidation of lignin obtained by corn stover:

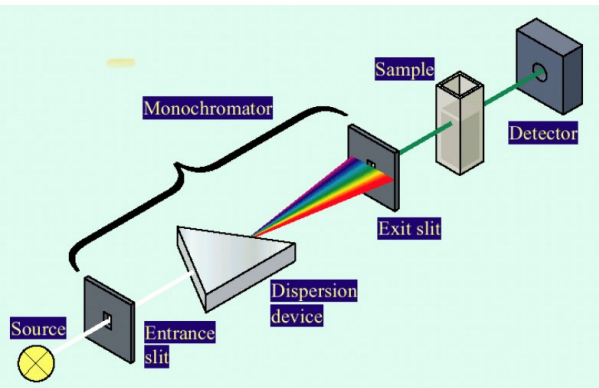

Figure 12: Basic design of UV-vis spectrophotometer. ${ }^{14}$

Next, the photoelectrochemical oxidation of lignin extracted by corn stover was carried out and the solution samples were characterized using UV-vis spectroscopy. UV-vis absorption spectroscopy is the measurement of the attenuation of a beam of light after it passes through or reflects from a sample surface (Figure 12). Different structures of molecules absorb different wavelengths from the light source. According to Planck's equation $(E=h \cdot c / \lambda)$, the shorter the wavelength, the more energetic the photon, which are the particles that make up light.

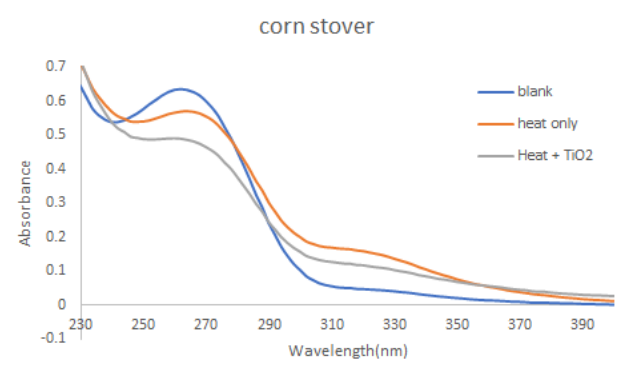

Figure 13: UV-vis absorption spectrum of corn stover.

In Figure 13, the UV-vis absorption level decreased around a wavelength of $260 \mathrm{~nm}$ and increased around $320 \mathrm{~nm}$. This change implies that the molecular structure was altered so that the molecule absorbs lower energy. This absorption data could indicate that lignin is oxidized photochemically or thermochemically under the illumination of visible light. In the basis of the previous study, the observation of lignin degradation can monitor the absorption band between $310 \mathrm{~nm}$ and $320 \mathrm{~nm}$. This specific wavelength can be the evidence of the presence of a carbonyl bond or ethylene type double bond in conjunction with benzene groups. ${ }^{15}$ Therefore, it was concluded that photoelectrochemical reactions using solar energy can be used as a pretreatment for depolymerization of lignin in mild conditions. The photochemical reactions of lignin are currently under investigation.

\section{- Conclusion}

Among the three fruits, raspberry, blackberry, and blueberry, raspberries showed the strongest absorption in the visible range, and thus were chosen for the dye sensitized solar cells to utilize abundant visible light in solar energy. After fabricating the DSSC with $\mathrm{TiO}_{2}$ paste and raspberry coating, electric currents were measured in various light intensities and light colors. As a result, shorter distances from the light source showed stronger light intensities and stronger electric currents. In the measurement with different light colors, DSSCs showed the strongest electric current in blue light, besides white light, which can be explained with UV-vis absorption spectrum showing that raspberry has an absorption peak at $508 \mathrm{~nm}$ wavelength. In the photoelectrochemical reaction of corn stover with DSSC, a UV-vis absorption spectrum change was observed. The peak at $270 \mathrm{~nm}$ decreased and the peak at $320 \mathrm{~nm}$ increased. This means that there was a molecular structural change in which the reaction's products absorbed less energy. Therefore, the experiment suggests the potential of lignin depolymerization using solar energy in mild conditions and at a low cost.

\section{- Acknowledgements}

Special thanks to Mrs. Hyun Yu as our mentor and supervisor for helping us use the UV-visible spectrophotometer and supervising the whole project at State University of New York College of Environmental Science and Forestry (SUNY ESF). We also thank Drs. Gyu Leem and Chang Geun Yoo at SUNY ESF, Syracuse, NY, USA for providing $\mathrm{TiO} 2$ paste, corn stover, and electrolyte solution. This work was supported in part by the USDA National Institute of Food and Agriculture, McIntire-Stennis project number: 1026335.

\section{References}

1. Tayyab, M., Noman, A., Islam, W., Waheed, S., Arafat, Y., Ali, F., Zaynab, M., Lin, S., Zhang, H. \& Lin, W. (2018). Bioethanol production from lignocellulosic biomass by environment-friendly pretreatment methods: A review. Appl. Ecol. Env. Res, 16, 225249.

2. Brebu, M., \& Vasile, C. (2010). Thermal degradation of lignina review. Cellulose Chemistry E Technology, 44(9), 353.

3. Li, S., Li, Z. J., Yu, H., Sytu, M. R., Wang, Y., Beeri, D., Zheng, W., Sherman, B., Yoo, C. \& Leem, G. (2020). Solar-Driven Lignin Oxidation via Hydrogen Atom Transfer with a Dye-Sensitized TiO2 Photoanode. ACS Energy Letters 5(3), 777-784.

4. https://blog.resourcewatch.org/2019/05/02/which-countries-usethe-most-fossil-fuels/

5. https://mahb.stanford.edu/library-item/fossil-fuels-run/

6. https://ourworldindata.org/air-pollution\#summary.

7. Rasmussen, M., \& Minteer, S. D. (2014). Photobioelectrochemistry: solar energy conversion and biofuel production with photosynthetic catalysts. Journal of The Electrochemical Society, 161(10), 
H647-H655.

8. Operation of a Grätzel cell. Retrieved from https://en.wikipedia. org/wiki/Dye-sensitized_solar_cell

9. Takechi, K., Muszynski, R., \& Kamat, P. V. (2009). Fabrication procedure of dye-sensitized solar cells. Retrieved on Feb.

10.Smestad, G. P., Gratzel, M. (1998). Demonstrating electron transfer and nanotechnology: a natural dye-sensitized nanocrystalline energy converter. Journal of chemical education, 75(6), 752.

11.Mittal, A., Katahira, R., Donohoe, B. S., Black, B. A., Pattathil, S., Stringer, J. M., \& Beckham, G. T. (2017). Alkaline peroxide delignification of corn stover. ACS Sustainable Chemistry E Engineering, 5(7), 6310-6321.

12.Galloway, K. R., Bretz, S. L., \& Novak, M. (2015). Paper chromatography and UV-Vis spectroscopy to characterize anthocyanins and investigate antioxidant properties in the organic teaching laboratory. Journal of Chemical Education, 92(1), 183188.

13.Solar radiation spectrum. Retrieved from https://commons wikimedia.org/wiki/File:Solar_Spectrum.png

14.Basic design of UV-vis spectrophotometer. Retrieved from http:// ssi.shimadzu.com

15.Janshekar, H., Brown, C., \& Fiechter, A. (1981). Determination of biodegraded lignin by ultraviolet spectrophotometry. Analytica Chimica Acta, 130(1), 81-91.

\section{- Author}

Alicia Leem is a current sophomore at Fayetteville-Manlius High School and a member of Yoo and Leem research groups at State University of New York College of Environmental Science and Forestry, Syracuse, New York since 2018. Her current research focuses on biomass conversion. She has volunteered during National Chemistry Week for the Central New York American Chemical Society (CNY ACS). In her free time, she enjoys reading, painting, and snowboarding.

Claire Lee is a current sophomore at Fayetteville-Manlius High School and a member of Yoo and Leem research groups at State University of New York College of Environmental Science and Forestry, Syracuse, New York since 2018. Her current research focuses on solar energy conversion. She enjoys science and hopes to enter the medical field. During her free time she enjoys drawing and running. 